\title{
Platelet Adhesion Comparison of Silk Fibroin Dissolved by Different Solvents
}

\author{
Helei Li ${ }^{1}$, Wei Tian ${ }^{1}$, Guangzhou Song ${ }^{1}$, Mengyao Ding ${ }^{1}$, Honggen Yi $^{1}$, Yin Yin ${ }^{2}$, Fenglin Dong ${ }^{3}$ and Jiannan Wang*1 \\ ${ }^{1}$ National Engineering Laboratory for Modern Silk, China
}

${ }^{2}$ Laboratory Animal Research Center, China

${ }^{3}$ Department of Ultrasonography, China

Received: 㘹: December 19, 2018; Published: 眥: January 04, 2019

*Corresponding author: Jiannan Wang, National Engineering Laboratory for Modern Silk, China

\begin{abstract}
Silk fiber is a natural protein with high purity, and can be easily processed into films, meshes and porous materials, which possesses good cytocompatibility and biodegradability, especially excellent water absorption and breathable. Base on the satisfactory properties, we prepared regenerated silk fibroin materials using neutral salt solvents dissolution with $\mathrm{CaCl}_{2}, \mathrm{Ca}\left(\mathrm{NO}_{3}\right)_{2}$ and LiBr, respectively (named SF-CaCl${ }_{2}, \mathrm{SF}-\mathrm{LiBr}$ and SF$\mathrm{Ca}\left(\mathrm{NO}_{3}\right)_{2}$ ), and investigated platelet adhesion ability to evaluate driving force of hemostasis. Results showed that platelet adhesion rate and platelet activity on the calcium salt dissolved silk fibroin film surfaces were significantly higher that on the SF-LiBr film. SEM images showed that platelets tended to aggregate on the $\mathrm{SF}-\mathrm{CaCl}_{2}$ and $\mathrm{SF}-\mathrm{Ca}\left(\mathrm{NO}_{3}\right)_{2}$ films.
\end{abstract}

Keywords: Silk Fibroin; Films and Sponges; Platelet Adhesion Rate; Platelet Activity

\section{Introduction}

Silk has rich sources and high purity, is composed of silk fiber core layer (silk fibroin) and sericin wrapped outer layer. Silk fibroin can be easily processed into various morphological materials, such as nanofibers, films, sponges, gels or nanoparticles [1-5], and has been widely studied for applications in extracellular matrix, tissue engineering scaffolds and drug delivery carriers, owing to its excellent biocompatibility and biodegradability [1-11]. On the other hand, silk fibroin contains more hydrophilic amino acids, such as serine, Tyrosine, glutamic acid, aspartic acid and lysine [1214], endowing silk fibroin fast water absorption. On the bleeding wounds, rapid water absorption of a material is beneficial for improving blood viscosity, and promoting platelet activation and aggregation, thus accelerating clotting. Otherwise, the functional groups - $\mathrm{COOH}$ from glutamic acid or aspartic acid, and $-\mathrm{OH}$ from serine or Tyrosine can interact with $\mathrm{Ca}^{2+}$ by coordination bonds and electrostatic interaction $[15,16]$. In the coagulation mechanism, it is well known that $\mathrm{Ca}^{2+}$ is a key clotting factors, which interacts with platelet surface phospholipids to activate thrombin, and then digests fibrinogen into fibrin, resulting in coagulation formation. Therefore, silk fibroin protein is worth considering for the development of hemostatic materials. Platelets are the drivers in cascade pathway for blood clotting. In the present paper, we explored platelet adhesion and aggregation activity on regenerated silk fibroin materials prepared by different dissolution mechanisms, expecting to provide valuable guidance for the development of silk fibroin blood contact materials.

\section{Materials and Methods}

\section{Preparation of Silk Fibroin Solution}

Raw silk was boiled in $\mathrm{Na}_{2} \mathrm{CO}_{3}$ solution three times to remove sericin, as described previously [9]. After degumming, silk fiber was dissolved in the following three neutral salt solvents (1) a ternary solvent $\mathrm{CaCl}_{2} \cdot \mathrm{CH}_{3} \mathrm{CH}_{2} \mathrm{OH} \cdot \mathrm{H}_{2} \mathrm{O}$ (mole ratio, $1: 2: 8$ ) at $70^{\circ} \mathrm{C}$, or (2) 9.3 $\mathrm{M}$ of $\mathrm{LiBr}$ at $65^{\circ} \mathrm{C}$ or $(3)$ molten $\mathrm{Ca}\left(\mathrm{NO}_{3}\right)_{2}$ at $85^{\circ} \mathrm{C}$, and stirred until completely dissolved. After dialyzing against deionized water, the mixed solution was concentrated and filtered to obtain silk fibroin aqueous solution (5\%,w:w).

\section{Preparation of Silk Fibroin Materials}

$5 \%$ of silk fibroin aqueous solution were mixed with polyethylene glycol diglycidyl ether (Sigma, USA) (1.0:0.8, w/w) and stirred to ensure entirely mixing. The thin films of silk fibroin were 
prepared by casting the mixed solution onto polyethylene dishes and air-dried at room temperature. The sponges of silk fibroin were prepared by freeze-dried at $-80^{\circ} \mathrm{C}$. Samples were impregnated in deionized water at $4^{\circ} \mathrm{C}$ for $72 \mathrm{~h}$ to remove unreacted residues, and then cut and put into 48 -well cell culture plates or $2 \mathrm{ml}(0.5 \times 2.0 \mathrm{~mm})$ centrifuge tubes, finally, were sterilized with gamma irradiation. Regenerated silk fibroin materials were named to $\mathrm{SF}-\mathrm{CaCl}_{2}, \mathrm{SF}-\mathrm{LiBr}$, $\mathrm{SF}-\mathrm{Ca}\left(\mathrm{NO}_{3}\right)_{2}$, respectively. Calcium alginate was used as a control.

\section{Platelet Adhesion Rate Testing}

Samples (in quintuplicate for sponges, in triplicate for films) were equilibrated with normal saline at $3^{\circ} \mathrm{C}$ for $2 \mathrm{~h}$, then was added $1 \mathrm{~mL}$ (in 48-well plate chamber for static adhesion) or $1.5 \mathrm{~mL}$ (in 2-mL tube for dynamic adhesion) fresh platelet-rich plasma (PRP) at a density of $5 \times 10^{5}$ cells $/ \mathrm{mL}$ (N1) and incubated at $37^{\circ} \mathrm{C}$ for $3 \mathrm{~h}$. The PRP was obtained by the method described in the previous literature $[17,18]$. The numbers of platelets remaining in PRP were ounted using a cell counter (N2). The platelet adhesion rate was calculated using the following equation, all samples were analyzed in quintuplicate. Following rinsing, the sponges from each well or tube was used for platelet activity analysis, and the films for scanning electron microscopy (SEM) observation.

$$
\text { Adhesion rate }(\%)=\frac{N_{1}-N_{2}}{N_{1}} \times 100 \%
$$

\section{Platelet Activity Assay}

Platelet activity was determinated by methyl thiazolyl tetrazolium (MTT) method, as described previously $[9,19]$. Samples were added with MTT at working concentration $50 \mathrm{mg} / \mathrm{mL}$ and incubated at $37^{\circ} \mathrm{C}$ for $4-6 \mathrm{~h}$. After removing the supernatant, 1 or $1.5 \mathrm{~mL}$ hydrochloric acid isopropyl alcohol was used to dissolve the purple formazan crystals. The absorbance of the supernatant was recored at $490 \mathrm{~nm}$ using a Synergy HT microplate reader (BIO-TEK, USA). All samples were analyzed in triplicate.

\section{Scanning Electron Microscopy}

Samples were fixed in $2.5 \%$ glutaraldehyde for $2 \mathrm{~h}$ and dehydrated using an ethanol/water gradient $(25,50,75$, and $100 \%)$. After air-drying in a fume hood and gold coating, platelet adhesion to each sample surface was observed on an S-4800 scanning electron microscope (SEM; Hitachi, Tokyo, Japan).

\section{Statistics}

Data are presented as mean \pm standard deviation of the mean. Comparisons of means were performed using one-way analysis of variance (ANOVA), followed by the independent sample t-test using SPSS 17.0 statistical software. Statistical significance was set at $\mathrm{p}<0.05$.

\section{Results and Discussion}

\section{Platelet Adhesion Observation on Silk Fibroin Films}

The platelet adhesion on the silk fibroin film surfaces is shown as Figure 1 Platelet adhesion to $\mathrm{SF}-\mathrm{CaCl}_{2}$ and $\mathrm{SF}-\mathrm{Ca}\left(\mathrm{NO}_{3}\right)_{2}$ was significantly more than to $\mathrm{SF}-\mathrm{LiBr} \mathrm{Ca}^{2+}$, a proved coagulation factor in cascade coagulation pathways, interacts with platelet surface phospholipids and activates thrombin to digest fibrinogen into fibrin, resulting in coagulation formation. There are a large amount of functional groups - $\mathrm{COOH},-\mathrm{NH}_{2}$ and $-\mathrm{OH}$ distributed on silk fibroin chain, which can interact with $\mathrm{Ca}^{2+}$ by electrostatic interaction and coordination bonds. After dissolution by $\mathrm{CaCl}_{2}$ and $\mathrm{Ca}\left(\mathrm{NO}_{3}\right)_{2}$, there was a small amount of chelated $\mathrm{Ca}^{2+}$ remaining in silk fibroin films. So, platelet adhesion was greater on the calcium salt dissolved silk fibroin film surfaces. From SEM images, it can be seen most platelets on $\mathrm{SF}-\mathrm{CaCl}_{2}$ and $\mathrm{SF}-\mathrm{Ca}\left(\mathrm{NO}_{3}\right)_{2}$ films were activated, extended microfilaments and microtubules, and displayed high aggregation activity.

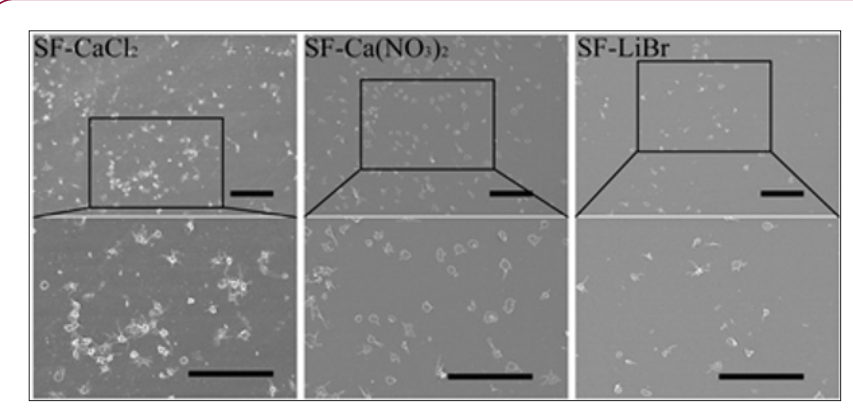

Figure 1: SEM images of platelets adhered to silk fibroin films. Bar $=20 \mu \mathrm{m}$.

\section{Platelet Adhesion Rate on Silk Fibroin Sponges}

As shown in Figure 2 the platelet adhesion rate on $\mathrm{SF}-\mathrm{Ca}\left(\mathrm{NO}_{3}\right)_{2}$ sponge (33\%) was similar to that on $\mathrm{SF}-\mathrm{CaCl}_{2}$ sponge $(39 \%)$, and both of them were higher than that on SF-LiBr sponge (24\%), owing to chelated $\mathrm{Ca}^{2+}$ in calcium salt dissolved silk fibroin. The platelet adhesion rate on calcium alginate $(50 \%)$ was the highest because of a large amount of $\mathrm{Ca}^{2+}$ distributed in calcium alginate materials. Under static condition, the platelet adhesion rate on SFLiBr sponge was significantly lower than calcium alginate, but there was no significant difference between the calcium salt dissolved silk fibroin and calcium alginate. Dynamic platelet adhesion was slightly improved.

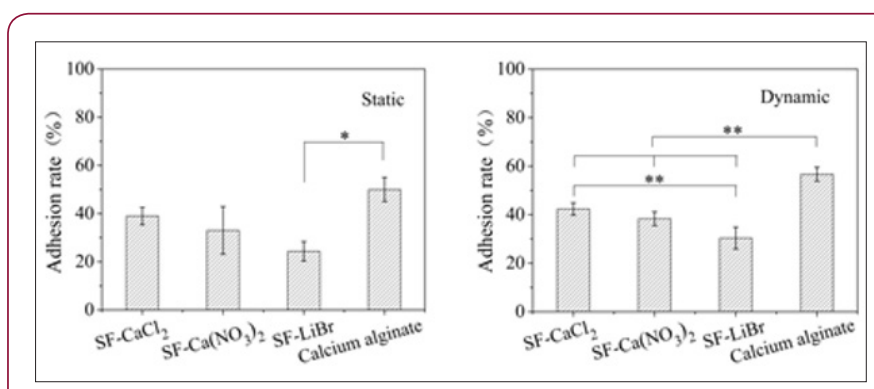

Figure 2: Platelet adhesion rate on silk fibroin sponges. ${ }^{*} \mathrm{p}<0.05,{ }^{* *} \mathrm{p}<0.01$.

\section{Platelet Activity on Silk Fibroin Sponges}

Platelets act the most important role in promoting blood coagulation, the strength of which is dependent on the platelet activity. As shown in Figure 3 platelet activities on $\mathrm{SF}-\mathrm{CaCl}_{2}$ and $\mathrm{SF}-\mathrm{Ca}\left(\mathrm{NO}_{3}\right)_{2}$ sponges were significantly higher compared with that on SF-LiBr sponge under whether static condition or dynamic 
condition, but lower than that of calcium alginate material. The results were consistent with the platelet adhesion rates.

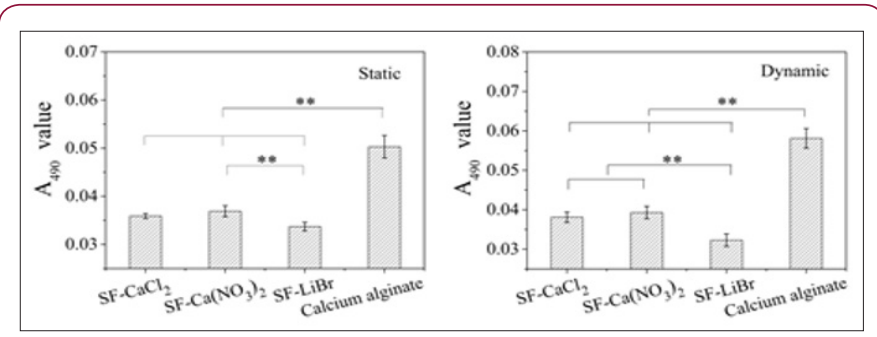

Figure 3: Platelet activity on silk fibroin sponges. ${ }^{* *} \mathrm{p}<0.01$.

\section{Conclusion}

Regenerated silk fibroin materials prepared by different dissolution strategies showed influences on suitable application. When using calcium salt dissolution to dissolve silk fibers, a small amount of $\mathrm{Ca} 2+$ chelated with silk fibroin molecules and remained in the silk fibroin after dialysis. It was a preferred method to prepare silk fibroin materials for the development of hemostatic materials, but not feasible to prepare anticoagulant materials, such as artificial blood vessels, intravascular stents or cardiac valves. The study of the paper provided a guidance for the applications of silk fibroin in blood contact materials.

\section{Acknowledgement}

This work was supported by National Natural Science Foundation of China [Nos 51473108, 51873141], Natural Science Foundation of Jiangsu Province of China [No BK20181192] and College Natural Science Research Project of Jiangsu Province of China [No 18KJA540001].

\section{References}

1. Dadras Chomachayi M, Solouk A, Akbari S, Sadeghi D, Mirahmadi F, et al. (2018) Electrospun nanofibers comprising of silk fibroin/gelatin for drug delivery applications: Thyme essential oil and doxycycline monohydrate release study. Journal of Biomedical Materials Research Part A 106(4): 1092-1103.

2. Tu FF, Liu YF, Li HL, Shi PG, Hao YX (2018) Vascular Cell Co-Culture on Silk Fibroin Matrix. Polymers 10(1): 39.

3. Viviana PR, Joana SC, Cristiana G, Sandra P, Hajer R, et al. (2018) Rapidly responsive silk fibroin hydrogels as an artificial matrix for the programmed tumor cells death. PLoS One 13(4): e0194441.

4. Hassani Besheli N, Mottaghitalab F, Eslami M, Gholami M, Kundu SC, et al. (2017) Sustainable Release of Vancomycin from Silk Fibroin Nanoparticles for Treating Severe Bone Infection in Rat Tibia Osteomyelitis Model. ACS Applied Material \& Interfaces 9(6): 51285138.

\section{ISSN: 2574-1241}

DOI: 10.26717/BJSTR.2019.12.002310

Jiannan Wang. Biomed J Sci \& Tech Res

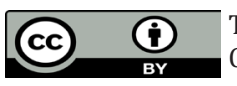

This work is licensed under Creative Commons Attribution 4.0 License

Submission Link: https://biomedres.us/submit-manuscript.php
5. Wei YL, Sun D, Yi HG, Wang JN (2014) Characterization of a PEG-DE cross-linked tubular silk scaffold. Textile Research Journal 84(9): 959967.

6. Diaz Gomez L, García González CA, Wang JM, Yang F, Aznar Cervantes S, et al. (2017) Biodegradable PCL/fibroin/hydroxyapatite porous scaffolds prepared by supercritical foaming for bone regeneration. International Journal of Pharmaceutics 527(1-2): 115-125.

7. Türkkan S, Atila D, Akdă A, Tezcaner A (2018) Fabrication of functionalized citrus pectin/silk fibroin scaffolds for skin tissue engineering. Journal of Biomedical Materials Research Part B: Applied Biomaterials 106(7): 2625-2635.

8. Ribeiro VP, Silva Morais A, Maia FR, Canadas RF, Costa JB, et al. (2018) Combinatory approach for developing silk fibroin scaffolds for cartilage regeneration. Acta Biomaterialia 72: 167-181.

9. Wang JN, Wei YL, Yi HG, Liu ZW, Sun D, et al. (2014) Cytocompatibility of a silk fibroin tubular scaffold. Materials Science and Engineering $\mathrm{C}$ 34: 429-436.

10. Liu YF, TuFF, Li HL, Shi PG, Yin Y, etal. (2018) Preparation, characterization and in vivo graft patency of a silk fibroin tubular scaffold. Materials Technology 33(3): 227-234.

11. Mao B, Liu C, Zheng W, Li X, Ge R, et al. (2018) Cyclic cRGDfk peptide and Chlorin e6 functionalized silk fibroin nanoparticles for targeted drug delivery and photodynamic therapy. Biomaterials 161: 306-320.

12. Wang JN, Yan SQ Lu CD, Bai L (2009) Biosynthesis and characterization of typical fibroin crystalline polypeptides of silkworm Bombyx mori. Materials Science and Engineering C 29(4): 1321-1325.

13. Yang GQ, Wu MY, Yi HG, Wang JN (2016) Biosynthesis and characterization of a non-repetitive polypeptide derived from silk fibroin heavy chain. Materials Science and Engineering C 59: 278-285.

14. Wu Y, Kang Z, Tian ZF, Wu MY, Wang JN (2017) Biosynthesis and characterization of recombinant silk-like polypeptides derived from the heavy chain of silk fibroin. Polymers 9(12): 669.

15. Rhee SH, Lee JD, Tanaka J (2000) Nucleation of Hydroxyapatite Crystal through Chemical Interaction with Collagen. Journal of the American Ceramic Society 83(11): 2890-2892.

16. Tang GX, OuYang KY, Zhou L, Liu Y, Zhang L, et al. (2015) Titanium Modification by Calcium Ion Chelated Polydopamine and Its Cytocompatibility. Journal of Inorganic Materials 30(10): 1075-1080.

17. Sun D, Hao YX, Yang GQ Wang JN (2015) Hemocompatibility and cytocompatibility of the hirudin-modified silk fibroin. Journal of Biomedical Materials Research Part B: Applied Biomaterials 103(3): 556-562.

18. Hao YX, Sun D, Wang QY, Dong FL, Zhang GY, et al. (2015) In vitro blood compatibility evaluation of silk fibroin by chemical crosslinking. Materials Technology: Advanced Performance Materials 30(6): 327-331.

19. Sun XL, Hao YX, Wang QY, Dong FL, Wang JN (2016) Cell growth and proliferation on the interface of a silk fabric tubular scaffold. Textile Research Journal 86(20): 2193-2201.

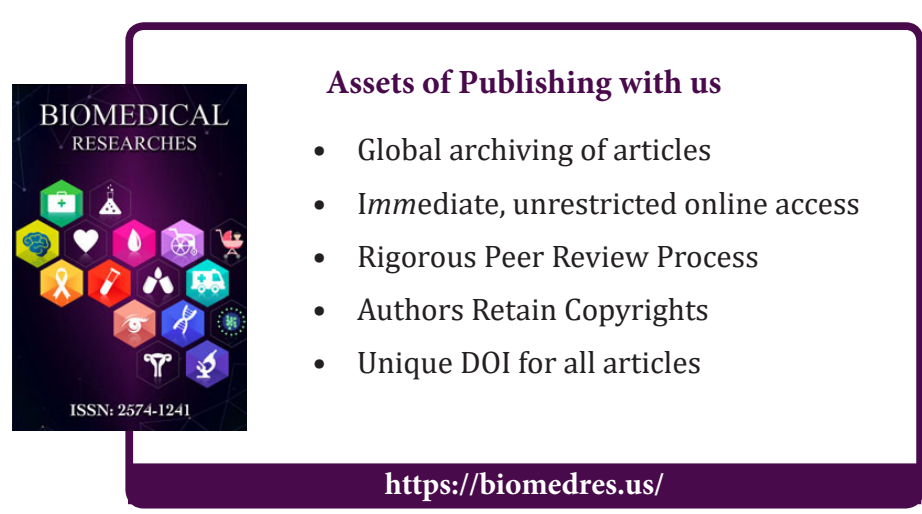

Cite this article: Helei L, Wei T, Guangzhou S, Mengyao D, Honggen Y, Yin Y, Fenglin D, Jiannan W. Platelet Adhesion Comparison of Silk Fibroin Dissolved by Different Solvents. Biomed J Sci \& Tech Res 12(5)-2019. BJSTR. MS.ID.002310. DOI: 10.26717/ BJSTR.2019.12.002310. 